\title{
Challenging Professional Roles: Lay Carers' Involvement in Health Care in the Community
}

\section{Susan Pickard, Sally Jacobs and Susan Kirk}

\begin{abstract}
The bulk of care in the community is carried out by lay carers. Recent policy initiatives to support them in the United Kingdom are outlined. There remains evidence of significant gaps in support from professional health and social-care workers including community nurses. This paper reports three studies of lay carers: those caring for older people, carers of technology-dependent children, and home-care workers involved in the "direct payments" scheme. Findings are reported in the areas of decisions about appropriate caring roles, the lay-professional boundary, training and respite opportunities and the expertise of lay carers. Recommendations for policy and practices are made.
\end{abstract}

\section{Keywords}

Lay carers; Public policy; Caring roles

\section{Background: Redefining Professional and Lay Roles}

Care in the community has been constructed on the basis of professional support for lay carers; it is the latter who undertake the main responsibility for caring (Department of Health I989: 4). Lay care forms the context for the experience of community care, involving large numbers of individuals: approximately 5.7 million people in the UK or one in 8 adults (Rowlands and Parker 1998) are believed to be carers to some degree and just under 2 million carers are co-resident. Severely disabled older people and children are mainly cared for in their own homes and four-fifths of confused older people are receiving care in the community in private households. Yet only a third of such carers receive any sort of regular, defined as once a month (Dooghe I992), visit from statutory or voluntary services. Moreover, owing to the severe dependency of many such care-receivers, we can surmise that much of what carers have to do consists of tasks which can be defined as

Address for correspondence: $D r$ Susan Pickard, National Primary Care RED Centre, University of Manchester, Fifth Floor, Williamson Building, Oxford Road, Manchester, MI3 9PL. E-mail: susan.pickard@man.ac.uk 
health care (Rowlands and Parker 1998) and which we have defined in this study as ranging from changing dressings and administering medication to involvement in complex and technical acts such as renal dialysis.

In the area of disabled and chronically ill children there is evidence that parents are not only involved in providing care associated normatively with parenting but are in some instances in addition providing highly intensive and technical care for their children. This is because in recent years, due to medical advances, a small but growing subset of children have emerged who are dependent on medical technology for their survival. In order to care for their children at home, their parents are involved in providing and being responsible for types of care-giving that formerly would have been considered to be professional care (for example, changing tracheotomy tubes, caring for children dependent on assisted ventilation, giving intravenous infusions) (Kirk and Glendinning 1998).

Government policy over the last decade has reiterated the need to support carers. The Carers' (Recognition and Services) Act of I995 recognized that carers have needs of their own and the establishment of a National Carers' Strategy (Department of Health 1999a) represents the most ambitious attempt yet to support carers in their caring role. National Service Frameworks published to date all emphasize the need to support carers (Department of Health ig9gb, 2000) and the National Service Framework for Older People places particular emphasis on the need to support carers of older people (Department of Health 200I) and to establish systems to explore user and carer experience by April 2004.

Evidence indicates that carers certainly require this support: while carers' own health is adversely affected by caring responsibilities (Victor 1997), at the same time there are considerable levels of unmet need for nursing support (e.g. Henwood 1998). However, the current absence of any hard evidence about what tasks are being performed, by whom and in which contexts, means that the support carers are given by primary care professionals is worked out in face-to-face encounters at ground level without drawing from evidence and guidelines (Pickard et al. 2000).

While lay/professional boundaries are unclear and in many instances may be subject to individual negotiation, professional boundaries have also been subject to change over the past decade, with responsibility for certain activities, including activities that may have been central formerly to a professional's role, shifting from one professional group to another. Social services, in particular, have taken over certain activities that were once part of the remit of community nurses, perhaps the best-known example being that of bathing (see Twigg 1997: 69).

With the fragmentation of traditional family support networks and the change in professional roles, there are a growing number of paid lay carers employed to provide personal care in the place of family carers. One particular area of growth in this sector has been as a result of the introduction in I997 of "Direct Payments" (DP) schemes in which English local authorities have been enabled to make payments to disabled people giving them the financial ability to employ their own personal assistants (PAs) (and subsequently this has been extended to other groups including parent carers and 
older people). Although direct payments are intended to replace the "social" services provided by local authorities, personal assistants in the same way as family carers are likely to be involved in activities traditionally classed as health care and located within the remit of nurses and other health-care professionals (Glendinning et al. 2000a, 2000b, 2000c, 2000d).

Home carers have also been involved in caring in ways which overlap both with the roles of parents and with professionals. In the group in which we carried out research, families with children needing continuous ventilation had teams of carers who assisted and supported families often up to 24 hours a day, 7 days a week (even accompanying them on family holidays). Other families had workers coming into the home to care for their children overnight or for periods in the day. How these workers were funded and employed varied from area to area and their employers included hospitals, nursing agencies and community trusts. Carers were taught how to care for the needs of individual children, and in most cases this enabled them to substitute for parents, enabling them to have a complete break from caring (Kirk and Glendinning 1998).

In connection with these developments, and as a result of the lack of clarity and detailed information that exists about who is doing what in the community, assumptions, beliefs and expectations - about who should be doing what, when and how - assume a greater significance in informing the interaction between professionals and lay carers and influencing the type of services carers are offered (see Young 1977; Wilson 1991; Twigg and Atkin 1994, on "assumptive worlds").

\section{Aims and Methodology: A Comparison of Three Projects}

The paper draws on three separate projects which looked at a distinct group of lay carers in the home: older carers of older people; parent carers of technology-dependent children and home-care workers or PAs involved in the fledgling DP scheme (Kirk and Glendinning I999; Glendinning et al. 2000a, 200ob, 2000c, 2000d; Pickard and Glendinning 200I). This provides us with the opportunity to look across a range of different contexts in exploring the interfaces between lay and professional carers and, in addition, to compare and contrast the experience of paid lay carers with family carers.

Box I summarizes the major features of the three projects, indicating the main respondents in each study, with some descriptions of the study sites involved.

In each of these studies we collected, through a combination of methods including semi-structured interviews and focus groups, the perspectives of both professionals and lay carers in order to triangulate our data and to enrich our understanding of the experience of different groups working together. Common, unifying themes were decided in collaboration with all three researchers following their completion of the three separate projects. Data were then analysed for each project in accordance with these themes, with one of the researchers taking a lead role and working closely with the researcher who had been most involved with that individual project. Themes were further clarified in meetings in which all three researchers were present, 
Box I

Older carers of older people

Carers: Older people (70+) caring for frail older people half of whom had dementia, half of whom did not; $n=24$

Professionals: District nurses (DNs) and Community psychiatric nurses (CPNs), $n=24$

Location: two contiguous metropolitan HA areas

\section{Carers of technology-dependent children}

Carers: parents of 24 children

Professionals: wide range involved in supporting the child at home, including nurses and health-care workers; $n=3^{8}$

Location: north of England (recruited via three specialist children's hospitals)

\section{Direct payments study}

Carers: Personal assistants (PAs) of disabled people in receipt of direct payments from social services; $n=\mathrm{I} 5$

Users: recipients of direct payments with complex health and social care needs; $n=42$

Health professionals: wide range including district nurses, physiotherapists, chiropodists; $n=\mathrm{I} 3$

Location: 3 local authority areas in England running direct payment schemes

and in which contrasts and comparisons were further identified and discussed. The themes selected were as follows:

- an exploration of what roles/caring activities lay carers are fulfilling in the community;

- how boundaries are negotiated in practice between lay and professional domains, including both decision-making at key points and ongoing negotiations;

- professionals'/lay carers' perceptions of the appropriate lay/professional boundary;

- the nature of support offered to lay carers, including training and respite opportunities;

- the different types of knowledge and expertise possessed by lay and professional carers.

This paper focuses on a discussion of each of the above themes. It then concludes by looking at implications of the above for policy and practice using, as a framework, the aims of the carers' strategy. Our paper is aimed at both academics and practitioners.

\section{What Do Lay Garers Do?}

Our data indicate that lay carers associated with all three studies are carrying out not only personal and physical care tasks, but also, indeed, many highly complex and technical health-care tasks. 
Older carers are performing more nursing-type activities including giving medication and changing dressings, up to complex acts including renal dialysis, colostomy and fistula care and parenteral feeding, in many cases unsupervised (case I).

\section{Case I}

One older woman, caring for her husband who had renal failure, took part in a complicated routine involving changing bags, weighing them and monitoring the exchange, based only on observation of what she had previously seen her husband and the nurses doing. She explained how, to begin with, "I was nervous, I didn't want to start any infection because you have to be very very careful. But now I just take it for granted, I just do it. It's time to do it."

In addition to roles associated with normative caring (for example, playing, disciplining, dressing, bathing), parents were managing their children's illness or condition (for example, administering drugs, carrying out physiotherapy) which involved them in performing highly technical clinical procedures relating to their children's technology-dependence. These procedures included, inter alia, suctioning airways, changing tracheotomy tubes, giving injections and intravenous infusions, parenteral and enteral feeding, giving oxygen and peritoneal dialysis. They were continually monitoring and assessing their child's condition and adjusting therapies according to their observations of the child.

The home carers associated with these parents varied in what tasks they were trained to perform. Two were fully trained to care for children on ventilators (including tracheotomy tube changes, nasogastric feeding, suction, etc.); one cared for a child with a tracheotomy at night and the other for a severely disabled child on total parenteral nutrition (TPN) overnight.

The personal assistants (PAs) of direct payments users were similarly involved in a range which was perhaps less hi-tech than some of the family carers described above but which included physiotherapy and chest physiotherapy, changing dressings, giving medication, giving injections, performing manual bowel evacuations, giving "medical" baths to people with skin conditions and performing personal care for individuals with HIV.

\section{How Are Decisions Made about What Lay Garers should Do?}

This section looks at the process of negotiation, including decision-making at key points and during ongoing points in the relationship between the carer and the professional.

The data reveal that decisions made and plans determined at key points tend to be made by professionals with lay care-givers having very little opportunity to influence these decisions. In this process decisions may be influenced by unspoken assumptions and expectations, particularly about the role of family care-givers (as we see in the next section).

In the case of older carers, the first point of contact with the professionals may occur when they are least well equipped to deal with it, when it may be 
precipitated by a crisis, such as a fall, following a stay in hospital on the part of the care-receiver; in other cases it may follow a visit to the GP by the carer, who has reached a point when they may be unable to carry on any longer without any formal support. In many cases, older carers have been caring for years, taking on particular roles and activities in a gradual process and only coming into contact with health services when a crisis occurs. As a result, when recalling this encounter or set of encounters, there is often confusion as to the roles of the professionals at this time and uncertainty as to how the plans and decisions made were in fact reached. With regard to assessment and reassessment, older carers describe their perception that the onus is upon them to initiate many of the changes that take place with respect to the balance of activities between themselves and the professional carers, particularly when they require greater input from professional carers, and some carers may be reluctant to ask for this (case 2).

\section{Case 2}

Mrs C cared for her severely disabled husband. She explains that the district nurses were first involved when her husband went into hospital. But she "wasn't aware really" of that process. She describes: "that assessment whatever it was at that time wasn't spelt out in such great detail. It may have been and I wasn't aware of it."

She explained that district nurses had come in once a week to bathe her husband but then his condition deteriorated and she needed more help. However, she said that the care workers needed a lot of persuasion before they agreed to this: "He then came at that time to kind of assess it and I felt at that time he needed an aweful lot of convincing."

Similarly in the case of technology-dependent children, choice about the extent of care-giving and negotiations with professionals are limited. The context in which contact with professionals is made is that children are either born needing the support of medical technology or they become dependent following an accident, illness or deterioration in condition. Generally, the parents take on performance of these roles in the hospital and there does not appear to be any negotiation; rather it is assumed that they will do it through a combination of beliefs about parental obligations and a strong philosophy of parental involvement in hospital care of sick children. Where parents feel unable to do certain tasks for their child, professionals will perform them if this is feasible, e.g. passing a nasogastric tube. But these can only be procedures required on an intermittent basis, as otherwise the implication is that the child could not go home. Indeed, parents of TD children perform all the clinical tasks and procedures their child needs with nurses only occasionally carrying out isolated procedures: in one case, a nurse did occasional wound swabs if needed; in the case of two other children (both with cystic fibrosis) a nurse specialist visited to do the monthly portacath flushes and she would give the first dose of an IV antibiotic course in case there was an anaphylactic reaction.

Personal assistants are in a different position to other lay carers as they are employees and the concept of choice is not considered particularly relevant. 
They are invariably brought in after the initial assessments have been carried out. Although it may be discussed at the initial interview, there does not appear to be a mechanism whereby the personal assistant formally agrees to undertake certain tasks and duties for their employer. But that, conversely, can lead to difficulties for the personal assistants.

Although personal assistants acknowledge that the care-receiver is firmly in control of the proceedings, some feel obliged, like family carers, to undertake certain tasks or duties which may be beyond their skills, which may comprise tasks they are averse to doing or which may encroach upon their own personal or family duties or responsibilities (case 3). However, in longterm caring relationships their role often comes to approximate to that of the family care-giver, with trust, confidence and loyalty characterizing both sides.

\section{Case 3}

One PA was asked to do chiropody even though she wasn't happy about it.

"In some situations, I've been forced to do something I've not felt like doing, like cutting toenails in the dark with no light on. They said, 'I don't want the light on,' and I'm saying, 'I'm sorry I can't do that.' 'Well you're going to have to.' So without causing an argument or whatever... That person insisted on a bit of blackmail, 'Well who else will I get to do my nails?' You're the only one I feel that can do them." "'

\section{Perceptions of the Appropriate Lay/Professional Boundary}

It is clear then that lay carers are involving themselves in a wide range of health-care activities some of which may once have been located within the domain of professionals. What do professionals make of this? In fact, our studies indicate there is a wide range of approaches which occupy broadly three positions:

- At one extreme, some professionals maintain that there are a range of activities which should only be performed by professionals (this includes activities that we know from our three studies lay carers are in fact carrying out).

- In the middle position, other professionals claim that carers are capable of being trained on a wide variety of tasks, although certain activities should more appropriately be performed by professionals.

- At the other extreme, some professionals suggest that carers are trainable in the entire range of activities and that in certain activities they are ready to concede that they may have a greater expertise than professionals themselves.

Those health professionals who believe that lay carers are not and should not be doing any type of health-care activity cite tasks including dressings, care of tracheotomies, catheterization, chest care, nursing assessments. In reality, 
the only activity that our data indicate carers are not currently undertaking is formal nursing assessments (although in some cases, carers frequently assess the care-receiver's condition and adjust therapies/care-giving in accordance).

Some nurses make the distinction between things that could be appropriate to delegate to lay carers and things that are not. For example, one district nurse suggested that dressings should be done by professionals only, because only with training is it possible to recognize signs of infection. But she takes this a step further and suggests that nurses' professional scrutiny is valuable for the smaller things too:

"even when you are doing something as simple, or what might appear as simple, as doing a bath every day you're also checking for, say, pressure areas and all sorts of things and if you haven't been trained you might not look for these things and know it's appropriate to contact the doctor about them." [DN in the direct payments study]

Other health professionals point out that lay carers are entirely trainable and that their involvement in this kind of care-giving is therefore to be welcomed. Indeed, some nurses indicate that lay carers are sometimes in possession of greater expertise than they are themselves. One nurse describes:

"We have one chap who looks after his wife who enjoys that role so much that he takes on more than we wanted him to take on... He recatheterizes - she has a suprapubic catheter. A lot of nurses can't do that. We have to be specially trained to do that. He recatheterizes ... she has gastric feeding ... He supervises her feeding, he cleans round the gastric feed." [DN in older carers study]

Older carers speak themselves about how they feel obliged to care because of the ties of duty, obligation and reciprocity that extend back over a whole lifetime (Pickard et al. 2000).

Similar feelings of obligation and duty are experienced by parents of TD children, as several parents testify,

"You've had the baby, you have to be responsible... I've had him, he's mine." [Mother of baby who receives monthly IV infusions for an immunological disorder]

Such obligations are recognized by professionals,

"I think mums sort of have this feeling that they have to do things for their children, because they want to ... if it's got to be done then they want to do it ... and so in a lot of cases I think the pressures are also put on mums to do everything." [Community children's nurse]

\section{Support for Carers}

This section looks at the support that carers receive to equip them in their caring role and also to support them as individuals with needs of their own. 
It deals with both aspects separately, looking at training first and then "care for carers" or respite provision.

\section{Training}

Where procedures are highly technical training is often very good and may be followed up by regular monitoring, particularly in the case of parent carers.

In the majority of cases of technology-dependent children in our study, both parents and home carers underwent a fairly formal teaching programme in the hospital. Home carers maintained their skills through attending courses. Some parents' practice was audited by specialist nurses based within the hospital. Others were either observed during a visit (informally) or indirectly through the professional monitoring the child's condition. Ensuring safe practice by parents was an element stressed by professionals.

In the case of older people, on-the-spot training consisted of older carers watching and learning from DNs. One DN recalled, of a carer looking after her husband:

"She would say G's dressing fell off yesterday so I just reapplied it the way you did it . . . she said I don't want to call you out, so I've just rebandaged it. Which I felt she did well. It was never really discussed. It was just she would say, 'Are you happy with what I've done?' And I would say, 'yes"'. [DN in older carers' study]

By contrast, training for procedures that may be complex but less technical is often sparse or inadequate. There is no training of personal assistants. In the case of disabled people using direct payments, such training may be perceived to be desirable where many users express a wish to train up their personal assistants according to their own unique specifications (case 4).

Any other training made available for PAs appears to have been of variable quality. Sometimes they were trained informally by health professionals; sometimes they were not, in a process which seemed very hit-and-miss.

Where direct payment users express a desire to train their personal assistants in more formal ways, for example, for more complex techniques or for issues of health and safety, this is often very hard to do (case 5).

\section{Case 4}

One direct payment user felt that there were advantages and disadvantages connected to training people himself. On the one hand, he explained that he wanted someone who had done it before as it wouldn't be such a shock to their system. Paradoxically, he also felt that he did not want someone who had done this type of work before as he didn't want somebody else's habits imposed on him. Consequently, he trains his personal assistants himself. For example, he has made personal assistants aware of pressure areas and pressure sores and has told them if they notice red marks they must tell his wife who will in turn inform the nurses if necessary. He has trained them to lift and roll and get him into a wheelchair if necessary. 


\section{Case 5}

One direct payment user explained that she would like more professional training for her personal assistant and support from health professionals around respiratory care. This would include training for her personal assistant on ventilators. Frustratingly, she can't find anyone to do training, even though she is willing to pay.

Several personal assistants point out that more training would be very desirable, for a variety of reasons, including continuity and convenience for the user and career development for themselves, as well as the fact that they tend to feel isolated without any contact with other PAs like themselves. One comments: "I use a lot of my own discretion but nobody's told me how to think things or do things." Another says training would be good, possibly leading to a formal qualification such as the NVQ.

As well as receiving no formal training, the care provided by lay carers (other than parent carers) is not monitored and there is no professional regulation of paid carers.

\section{"Care for carers"}

In this section we focus on respite provision. As Caring about Carers declares:

A break from caring is invaluable in reducing the psychological and emotional stress faced by many carers. Access to support services and breaks can also help carers to continue providing the support they give to a sick, disabled or elderly person. (Department of Health ig99a: 58)

In the case of the family care-givers in our three studies, the support services offered were commonly in the form of respite care based in institutions outside the home. However, this is generally the least acceptable form of support for our respondents. While respite has been seen to be particularly important for carers of people with dementia, in that this condition places considerable burdens on the carers (see, for example, Parker 1997) in our sample it was generally restricted to the individual with dementia being placed temporarily in a nursing home. Alternatives such as night-sitting services, which many carers described as being infinitely preferable, were not offered. Several carers of individuals with dementia reported bad experiences with respite, whereby care-receivers often suffered health crises including broken hips or limbs or emerged from respite homes in a worsened condition, that is, more forgetful and confused.

For parents of technology-dependent children, while health-care professionals did not play a major role in the clinical/nursing care of the children, their role, like that of CPNs for carers of older people with dementia, was largely one of giving advice and information and emotional support to lay carers. 
"Actual nursing care, the actual hands-on care tends to be done by the parent, very much. And I think we're just there as a support and a coordinator." [District nurse]

At the same time, respite was often not an option for the parents because, owing to the particular nature of their expertise, it was extremely difficult to find individuals with the necessary skills and experience to substitute for them.

Experiencing a different set of challenges, by contrast, personal assistants did not feel supported in terms of issues they faced with regard to their employer and were unable to derive any support from networks of peers, as would be more likely to exist among professional groups.

This lack of support may cause particular difficulties for personal assistants encountering situations in which their employers' expectations surpass the personal assistants' capabilities or place considerable demands on them emotionally.

\section{Lay Expertise}

Often lay carers acquire a considerable degree of expertise in particular procedures (which may be greater than that of many health professionals in relation to specific tasks or individuals). For example, they may know the way to touch, lift or bathe the care-receiver in ways that cause least distress and discomfort.

In the study of technology-dependent children, parents often had a far greater level of expertise in certain procedures than the district nurses (who lacked training in specialist, paediatric procedures). Indeed, nurses sometimes claimed that they learned from carers:

"They come to us and say, 'Well, what should we do?' And I mean we, to be quite honest, we're out of our depth. They've usually been taught procedures and are, well, competent, more competent than we are really, when they come home. But I would say that the parents know more about the technical procedures than we do: they teach us!" [District nurse]

PAs become acquainted with the person they are caring for to the extent that they interpret and advocate for them in the presence of health professionals and also come instinctively to know what they mean or what they want (case 6).

Case 6

One direct payment user explained that her personal assistant had to be able to read her well in order to know if she were tiring and to know the ways in which she wanted things done. Since this user also faced the problem of suffering from short-term memory loss, she needed constant reminders of issues which needed to be raised and things which needed to be done, and relied on her PA for this. 


\section{Case 7}

The PA of one direct payment user always accompanied her employer into hospital. She explained, comparing her approach with that of the nurses, "I mean the person you work for-you obviously know but they don't know how to handle them. You lift up somebody's arm and it may hurt or something like that and you've got to know how to handle each individual person."

It is also quite often the case that when the disabled user goes into hospital, the personal assistant comes to the hospital on a daily basis and continues to perform all the personal care needed (case 7).

Care-giving by lay carers may be characterized by a different approach to that of professionals, where professionals are experts on the disease trajectory and lay carers are expert on the individual themselves. It is often claimed that professional carers and lay carers can be distinguished by the fact that lay carers "care about" rather than merely "care for" the care-receivers (Parker 1980; Graham 1983). What, if anything, characterizes these distinct approaches?

Our data indicate that the familial care-giving relationship is characterized by several features, more or less shared by all lay carers in this study and which distinguished them from the relationships professionals have with the care-receiver. For family carers, caring is part of an emotional relationship in which the act of caring can be described as an expression of love or of duty, sometimes, as in the case of older people, containing within it the experience of loss of a partner. It does not have constraints in terms of time in which it takes place or in terms of where it takes place: homes can be colonized by medical equipment to the extent that they resemble hospitals. Spontaneous, unexpected events or crises can occur at any time and as a result of this in some cases the experience is shot through by fear or anxiety. This contrasts strongly with the experience of professional carers.

However, while lay carers build up a considerable degree of expertise in terms of caring for one individual, this expertise may be implicitly or explicitly devalued by professionals seeing it as an in-depth experiential knowledge of an individual rather than generalizable knowledge that can be applied to others. In other words, it is the deficiencies of lay care-giving, as compared with professional care-giving, that may be highlighted, as opposed to their unique strength.

In some cases, nurses seem happier to train for emergency or crisis use only, stressing that while procedures may be taught, the holistic knowledge behind these procedures cannot. Thus, while it is possible for lay carers to gain a high level of competence in the case of individuals, this is not the kind of knowledge that is transferable. As one district nurse, associated with the technology-dependent children sample put it,

"I think almost anyone can be taught the technical bit and then it's the same with nursing... I often say you can teach a monkey to do that." 
Consequently, family carers and lay, paid carers, despite their expertise, often express the view that their skills are devalued by professionals. As one paid home carer expressed it,

"Sometimes you feel like worthless ... you think, oh, you're okay to look after his needs and you're okay to be given the responsibility of caring for this child, you're with this child for like 37 hours a week, but you don't know anything. And sometimes you feel like saying excuse me! But you get used to it after a while. But you're not a professional, I'm not classified as a professional . . because . . . you don't need a qualification to do the job. And it gets overlooked sometimes."

\section{Conclusions}

The Carers' Strategy (Department of Health i999a) recognizes that carers need to become real partners with service agencies; that they need support from health, social care and voluntary organizations in fulfilling their role and that they have care needs of their own which must be recognized and taken on board, for example in the provision of respite care. In this paper, we have argued that lay carers are carrying out many complex and highly technical health-care activities within the home, some of which may have previously been carried out by health-care professionals. Negotiations between lay and professional carers are very much dominated by professionals and choice in practice is restricted for lay carers. One of the factors restricting choice is the fact that ideas of carers' roles are influenced by certain expectations and assumptions (held by both professionals and lay carers) such as views about what constitutes a good parent or a good spouse in terms of caring roles. Lay carers possess a considerable degree of expertise which contrasts with that possessed by professionals, the former being unique and person-centred as opposed to the latter's generalizable, scientific knowledge. Support for lay carers in the form of training is adequate, particularly for parent carers. Older carers learn procedures on the spot by watching nurses. For personal assistants there is a need for training to be available (although not obligatory) as and when the PAs and their employers choose this. Respite provision, however, being institutionally based, is not of a kind that is generally satisfactory to either parent carers or older carers.

\section{Recommendations}

The foundation of the government's Strategy for Carers entails their becoming real partners with the professionals who support them in their role. In order for this to happen we recommend:

- Health-care professionals first need to be fully aware of lay carers' involvement in a wide variety of caring tasks in the community, including complex and highly technical health-care activities.

- Health-care professionals need to acknowledge that lay skill and expertise, although of a contrasting nature to that possessed by professionals, is of a complementary kind that makes it possible to construct valuable 
interlocking relationships between lay and professional carers within the community. This may mean a reassessment of the roles currently played by health-care professionals to ones focusing on assessments and training.

- If choice is to become a reality for family carers, then expectations and assumptions connected with specific carer/care-receiver relationships should not influence assessments of the appropriateness of carers' involvement in caring and the degree of support offered by service agencies.

- Support should be offered of a kind that is appropriate to the individual situations, including training facilities and respite opportunities constructed around the needs and preferences of individual care-dyads. Both these concerns will be met if family carers are supported to become equal partners in planning and decision-making.

- Clearly, PAs are in a somewhat different position to that of family carers. However, in that their contribution takes on many characteristics of family care-givers, it would be appropriate for them to be supported, perhaps within the Direct Payments Initiative. Formal networks based perhaps around training needs PAs and home-care workers to discuss the expectations concerning their role, which may be subject to change over a period of time and which will consequently enable them to construct long-lasting relationships with direct payments' users in the community.

\section{Acknowledgements}

We would like to acknowledge the contribution of Professor Caroline Glendinning, NPCRDC, for her comments on drafts of this paper. All three projects on which this paper is drawn were undertaken under her guidance and supervision.

\section{References}

Department of Health (1989), Caring for People: Community Care in the Next Decade and Beyond, London: HMSO.

Department of Health (I999a), Strategy for Carers, London: HMSO.

Department of Health (I999b), National Service Framework for Mental Health, London: DoH.

Department of Health (2000), National Service Framework for Coronary Heart Disease, London: DoH.

Department of Health (200I), National Service Framework for Older People, London: DoH.

Dooghe, G. (1992), Informal caregivers of elderly people: a European Review, Ageing and Society, I2: 369-80.

Glendinning, C., Halliwell, S., Jacobs, S., Rummery, K. and Tyrer, J. (200oa), Bridging the gap: using direct payments to purchase integrated care, Health and Social Care in the Community, 8, 3: I92-200.

Glendinning, C., Halliwell, S., Jacobs, S., Rummery, K. and Tyrer, J. (20oob), New kinds of care, new kinds of relationships: how purchasing services affects relationships in giving and receiving personal assistance, Health and Social Care in the Community, 8, 3: 2OI-II.

Glendinning, C., Halliwell, S., Jacobs, S., Rummery, K. and Tyrer, J. (200oc), Buying independence: using direct payments to integrate health and social services, Bristol: Policy Press, pp. I-53. 
Glendinning, C., Rummery, K., Halliwell, S., Jacobs, S. and Tyrer, J. (20ood), Buying independence: using direct payments to purchase integrated health and social services, Executive Summary i7, National Primary Care Research and Development Centre, University of Manchester.

Graham, H. (1983), Caring: a labour of love. In J. Finch and D. Groves (eds), A Labour of Love: Women, Work, and Caring, London: Routledge and Kegan Paul.

Henwood, M. (1998), Ignored and invisible? Carers' experience of the NHS, London: Carers' National Association.

Hockey, J. and James, A. (I993), Growing up and Growing Old, London: Sage.

Kirk, S. and Glendinning, C. (I998), Trends in community care and patient participation: implications for the roles of informal carers and community nurses in the United Kingdom, Fournal of Advanced Nursing, 28, 2: 370-81.

Kirk, S. and Glendinning, C. (1999), Supporting Parents Caring for Technology Dependent Child, Research Report, National Primary Care Research and Development Centre, University of Manchester.

Parker, G. (1997), Coping with caring for a person with dementia. In F. Hunter (ed.), Dementia: Challenges and New Directions, London: Jessica Kingsley.

Parker, R. (I980), The State of Care, Jerusalem: Joint (JDC) Israel Brookdale Institute of Gerontology and Adult Human Development in Israel.

Pickard, S. and Glendinning, C. (200I), Older Carers of Frail Older People and the Interfaces with Primary Care Services, Executive Summary 21, National Primary Care Research and Development Centre, University of Manchester.

Pickard, S., Shaw, S. and Glendinning, C. (2000), Health care professionals' support for older carers, Ageing and Society, 20: 725-44.

Rowlands, O. and Parker, G. (1998), Informal Carers, Social Survey Division, London: HMSO.

Twigg, J. (1997), Health and Health Care in Later Life, Milton Keynes: Open University Press.

Twigg, J. and Atkin, K. (1994), Carers Perceived: Policy and Practice in Informal Care, London: Open University Press.

Victor, C. (I997), Community Care and Older People, London: Stanley Thornes.

Wilson, G. (I99I), Models of ageing and their relation to policy formulation and services, Policy and Politics, I59, I: 37-47.

Young, K. (I977), "Values" in the policy process, Policy and Politics, 5, 3: I-22. 